\title{
A cost-benefit analysis of foot and mouth disease control program for smallholder cattle farmers in Cambodia
}

\author{
Socheat Sieng ${ }^{1}$, Ian Patrick ${ }^{2}$, Stephen Walkden-Brown ${ }^{3}$, and Chetra Sar ${ }^{2}$ \\ ${ }^{1}$ Livestock health and biosecurity Freelance Consultant \\ ${ }^{2}$ Affiliation not available \\ ${ }^{3}$ University of New England
}

March 29, 2021

\begin{abstract}
The Cambodian government is attempting to mobilise government, donor and private sector funding to implement a coordinated FMD vaccination program (FMDVP). A necessary first step is to convince the farmers of the benefits of participating in and potentially financially supporting this program. Information was collected from 300 farmers in order to estimate the on-farm benefits and costs of their participation in an FMDVP. Implementing a successful vaccination program is difficult, and farmers understand from previous experience that there may be institutional, social, technical and financial constraints which limit its success. A benefit-cost analysis needs to take into account that outbreaks do not occur every year, not all cattle will be successfully vaccinated, not all sick animals successfully treated and sometimes sick animals simply sold. This study sensitises these variables in order to give a realistic estimation of the farmer participation benefits in an FMDVP. A general result is that it is worthwhile for farmers to participate in the FMDVP if there are average annual outbreaks, or at least two major outbreaks, in the ensuing five years. However, the results are influenced by the interaction of vaccination success and treatment success and coverage. Ineffective coverage and poor treatment of sick animals reduce the benefits of an FMDVP. It is also important that farmers do not sell sick stock and, if they do, that they are able to breed replacements rather than purchase replacements. There are many factors in the smallholder cattle farming system that will influence the success of an FMDVP; farmers will only choose to participate if they can be convinced of the short and long-term economic benefits.
\end{abstract}

\section{Hosted file}

FMD Vac Cost-Effective 24032021.pdf available at https://authorea.com/users/401086/ articles/515737-a-cost-benefit-analysis-of-foot-and-mouth-disease-control-program-forsmallholder-cattle-farmers-in-cambodia

\section{Hosted file}

FMD Vac Cost-Effective-Tables.pdf available at https://authorea.com/users/401086/ articles/515737-a-cost-benefit-analysis-of-foot-and-mouth-disease-control-program-forsmallholder-cattle-farmers-in-cambodia

\section{Hosted file}

FMD Vac Cost-Effective-Figures.pdf available at https://authorea.com/users/401086/ articles/515737-a-cost-benefit-analysis-of-foot-and-mouth-disease-control-program-forsmallholder-cattle-farmers-in-cambodia 